Eliana Sousa Silva

O contexto das práticas policiais nas favelas da Maré: a busca de novos caminhos a partir de seus protagonistas

Tese De Doutorado

DEPARTAMENTO DE SERVIÇO SOCIAL Programa de Pós-graduação em Serviço Social 


$$
\text { Pontifícia Universidade Católica }
$$

Eliana Sousa Silva

\section{O contexto das práticas policiais nas favelas da Maré: a busca de novos caminhos a partir de seus protagonistas}

Tese apresentada ao Programa de PósGraduação em Serviço Social da PUC-Rio como requisito parcial para a obtenção do título de Doutora em Serviço Social.

Orientadora: Denise Pini Rosalem da Fonseca 


$$
\text { Pontifícia } \text { Universidade }_{\text {Do Rio de Janeiro }}
$$

Eliana Sousa Silva

\section{O contexto das práticas policiais nas favelas da Maré: a busca de novos caminhos a partir de seus protagonistas}

Tese apresentada ao Programa de Pós-Graduação em Serviço Social da PUC-Rio como requisito parcial para a obtenção do título de Doutora em Serviço Social. Aprovada pela Comissão Examinadora abaixo assinada.

Profa. Denise Pini Rosalem da Fonseca

Orientadora

Departamento de Serviço Social - PUC-Rio

Prof. ${ }^{a}$ Myrtes de Aguiar Macêdo

Departamento de Serviço Social - PUC-Rio

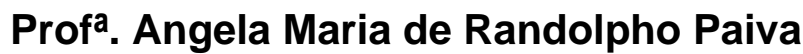

Departamento de Sociologia - PUC-Rio

Prof. Luiz Eduardo Bento de Mello Soares Universidade do Estado do Rio de Janeiro - UERJ

Profa. Silvia Ramos Universidade Cândido Mendes - UCAM

Prof ${ }^{\text {a }}$ Mônica Herz

Vice-Decana de Pós-Graduação do Centro de Ciências Sociais - PUCC-Rio

Rio de Janeiro, 14 de outubro de 2009 
Todos os direitos reservados. É proibida a reprodução total ou parcial do trabalho sem autorização da universidade, da autora e do orientador.

\section{Eliana Sousa Silva}

Graduou-se em Letras Português-Literaturas pela Universidade Federal do Rio de Janeiro, UFRJ, em 1987. Cursou Mestrado em Educação pela Pontifícia Universidade Católica do Rio de Janeiro, PUC/RJ, em 1995. Tem experiência de elaboração e implementação de projetos sociais voltados para as áreas de favelas no Rio de Janeiro. Na Universidade Federal atua como Diretora da Divisão de Integração Universidade Comunidade, da Pró-Reitoria de Extensão.

Ficha Catalográfica

Silva, Eliana Sousa

O contexto das práticas policiais nas favelas da Maré: a busca de novos caminhos a partir de seus protagonistas / Eliana Sousa Silva ; orientadora: Denise Pini Rosalem da Fonseca. - 2009.

2 v. : il. (color.) ; $30 \mathrm{~cm}$

Tese (Doutorado em Serviço Social)-Pontifícia Universidade Católica do Rio de Janeiro, Rio de Janeiro, 2009. Inclui bibliografia

1. Serviço social - Teses. 2. Favela. 3. Cotidiano.

4. Segurança pública. 5. Representação.

6. Ação policial. I. Fonseca, Denise Pini Rosalem da. II. Pontifícia Universidade Católica do Rio de Janeiro. Departamento de Serviço Social. III. Título. 
Ao Renan da Costa Ribeiro, uma criança de 3 anos que, como tantas outras residentes das favelas cariocas, teve sua vida abreviada por razões as quais não pode conhecer

Ao Jailson de Souza, o homem da minha vida. Com ele foi possível aflorar o ser mulher que existe dentro de mim. Com ele vivo a aventura cotidiana de amar

Ao meu filho, João Aleixo, o ser que materializou a idéia de amor incondicional na minha vida. Com ele renovo a percepção da vida em espiral À Paula Pimenta e Rodrigo Luiz que, por razões e caminhos distintos, também se tornaram filhos muito amados 


\section{Agradecimentos}

É preciso agradecer e o farei, mesmo sabendo do risco de cometer o lapso de não mencionar todos os possíveis colaboradores desse trabalho.

À minha orientadora Denise Peni Rosalem Fonseca, por ter me incentivado, desde o primeiro dia que nos conhecemos, a buscar o doutorado como um caminho importante para a reflexão do meu trabalho engajado na Maré. Sou grata, ainda, pela orientação segura, o respeito e a confiança na forma autônoma e decidida com que encarei o desenvolvimento da pesquisa e, principalmente, pela solidariedade em todas as fases, algumas sofridas, da elaboração dessa investigação.

A CAPES, à FULBRIGHT e à PUC-RIO, pelos auxílios concedidos, sem os quais a realização desse trabalho teria sido bastante prejudicado.

À Joana Maria F. Silva, secretária do Departamento de Serviço Social. Por sua dedicação e cuidado na orientação aos alunos sobre o processo administrativo que precisa ser cumprido. Serei eternamente grata.

Aos pesquisadores da Maré, jovens universitários, que atuaram no levantamento dos dados do campo junto aos moradores da Maré: Adriana Santos, Maria Aparecida Oliveira, Rachel Mizael Santos, Elma Avelino da Cruz, Aline Araújo Torres, Douglas Cordeiro da Silva, Lilian Dutra Angélica, Adriana dos Santos Silva, Élcio Alves da Silva, Mônica Benício, Geandra Nascimento, Shirley Rosendo, Sueli Vidal, Maria Aparecida da Silva, Viviane Melquíades, Verisomar da Glória, Aline Campos e Carmelita Ferreira. Um carinho enorme por cada um, com a admiração pelo esforço de fazer acontecer esse trabalho na Maré.

À Carla Santino, profissional oriunda da Maré, pela criação dos formulários eletrônicos para armazenamento de todos os dados coletados em cada segmento da pesquisa. Sou eternamente grata pela ajuda sempre.

À Juliana Santino, profissional oriunda da Maré, pela sistematização e preparação das tabelas a partir do material coletado, no Instituto de Segurança Pública, sobre 
os dados do Batalhão da Maré. Querida amiga de cujo crescimento intelectual tive o privilégio de participar até aqui.

À Ana Claudia Brito, profissional oriunda da Maré, pela leitura crítica e digitação de todos os dados coletados, meu carinho e agradecimento.

À Elionalva Sousa, profissional oriunda da Maré, pela colaboração imprescindível na pesquisa de campo.

À Sylvia Jussara Silva e Lucimar Ramos pela correção rigorosa de todo o texto. À Anna Paula Iannini, muito querida, pela formatação preciosa de todo o trabalho. Ao Dálcio Marinho, muito querido, pela dedicação e profissionalismo em todo o processo de elaboração e organização da base de dados da pesquisa de campo. Não tenho palavras para agradecer e dizer o quanto foi importante as contribuições trazidas pela experiência de muitos anos com pesquisa em Favelas.

Ao Jailson de Souza, pela revisão rigorosa, pela total disponibilidade em ler cada capítulo que escrevi e, respeitosamente, fazer sugestões, para que eu fizesse as mudanças; pelas contribuições ao problematizar as muitas e possíveis abordagens que se apresentavam, em função do tema que escolhi. Esse foi um rico e estimulante processo de escrita da tese, já que me colocava de maneira privilegiada em diálogo constante.

À Silvia Ramos, pela disponibilidade em sugerir referências bibliográficas sobre o tema da Segurança Pública. A descoberta de interesses de estudos comuns, quando das trocas que tivemos no período de escrita da tese, alegrou-me bastante e me animou a continuar este processo.

À Miriam Guindani, pela afinidade de idéias e trabalhos comuns na UFRJ. Pelas contribuições acadêmicas na leitura que fez do meu projeto de qualificação. Pela amizade e respeito que construímos desde o nosso primeiro encontro.

Ao Luiz Eduardo Soares, pela interlocução amiga e generosa durante tantos anos.

À Ângela Paiva e Myrtes de Aguiar, pelas contribuições acadêmicas na etapa de qualificação do projeto e por serem professoras tão dedicadas ao ofício que escolheram. 
Aos meus colegas de trabalho, especialmente a Laura Tavares, da UFRJ, onde trabalho há vinte e dois anos. Sou muito grata pelo carinho e apoio de todos da Pró-Reitoria de Extensão, PR-5, quando da minha entrada no doutorado. Sem dúvida, essa ajuda foi fundamental no sentido de poder me ausentar do trabalho no período de realização da tese.

Sou eternamente grata aos profissionais da segurança pública que conheci nessa aventura de tentar entender a ação da polícia militar nas favelas. Para mim, foi uma alegre e singela surpresa perceber que há muitas pessoas, como eu, que também querem sair da sua área de conforto e buscam dar sentido político e existencial ao que escolheram fazer nas suas vidas no campo profissional.

Aos primos Alberto Aleixo e Fernanda Gomes pela identidade de desejos em fazer acontecer na Maré um trabalho voltado para a segurança pública e o enfrentamento das diferentes formas de violência.

Aos profissionais do Observatório de Favelas, especialmente Raquel Willadino, Jorge Barbosa, Erasmo Carlos de Oliveira, Monique Carvalho, Fernando Lannes, João Ripper e toda equipe do Projeto Imagens do Povo, pela colaboração de cada um, de diferentes formas, para o meu processo de elaboração desse trabalho.

Aos meus queridos amigos (as) revelados (as) ao longo da minha vida: Silvia Soter Lia Rodrigues, Eblin Farage, Edson Diniz, Luiz Antonio Garcia, Carlos Henrique Sousa, Paulo Knauss, Nagib Said, Dálcio Marinho, Luiz Fernando Azevedo, Regina Pereira, Marivalda dos Santos, Marco Antonio Ramos, Aura Helena, Fábio Douglas, João Eduardo Nascimento, Onildo Oliveira e Rejane Galega de Sousa.

Aos meus pais João e Maria Aleixo. Sem eles eu não teria conseguido chegar até aqui. Com eles aprendo cotidianamente o quão é bela e singela a vida construída na luta por um mundo melhor.

Ao meu irmão Hélio Aleixo, às minhas irmãs Ana Inês, Eliene Sousa, Elza Sousa e Elionalva Sousa, por seu amor incondicional e por não reclamarem da minha ausência nas muitas reuniões e festividades da família, durante o período de escrita da tese. 
Aos meus sobrinhos e sobrinhas, já tenho tantos, pelo amor e a alegria manifestos em nosso convívio.

Aos que partilham o sonho de construir um vida melhor para os moradores da Maré, materializando suas ações, através da Redes da Maré, a minha gratidão a todos os integrantes da Instituição, dedicados tecedores.

Por fim, aos moradores das favelas da Maré, razão por que esse trabalho aconteceu. Maré: onde a minha vida se faz sentida. 


\section{Resumo}

Silva, Eliana Sousa; Fonseca, Denise Pini Rosalem da. O Contexto das Práticas Policiais nas Favelas da Maré: a busca de novos caminhos a partir de seus protagonistas. Rio de Janeiro, 2009. 460p. Tese de Doutorado - Departamento de Serviço Social, Pontifícia Universidade Católica do Rio de Janeiro.

Consiste em um estudo sobre a ação da polícia militar em favelas, especificamente no Complexo da Maré, conjunto de 16 (dezesseis) favelas localizado na zona da Leopoldina, Rio de Janeiro. O intento maior da pesquisa foi analisar as representações e práticas dos profissionais da segurança pública com foco na forma diferenciada como eles atuam em uma mesma cidade. O pressuposto é o de que a construção de novos paradigmas no campo das políticas públicas requer uma compreensão densa das representações e vivências presentes nesses espaços. O trabalho apresenta um olhar específico sobre a ação do Estado no campo da Segurança Pública. Analisou-se, em particular, a ação policial nos territórios populares, marcada pela diferença em relação aos espaços ditos formais. Procurou-se mostrar essa intervenção como um elemento integrado à lógica que norteia o estabelecimento e conservação da ordem social vigente, na qual as práticas diferenciadas afirmam características identitárias condicionadas por pressupostos sociais sustentados em hierarquias sociais distintivas e pela reprodução de um processo de privatização da soberania nas favelas conduzido por Grupos Criminosos Armados, em geral. Nesse quadro, o Estado, que deveria garantir a segurança pública de toda polis, age nos territórios favelados sem considerar os condicionantes e necessidades dos cidadãos. Essa postura naturaliza o uso da violência como eixo axial da estratégia policial para conter os grupos criminosos vinculados ao comércio de drogas no varejo, forma de crime transformada em prioridade absoluta de combate pelo Estado no espaço urbano brasileiro. Desse modo, a superação das formas de soberania diferenciadas na cidade e, em função disso, dos modos distintos de ação das forças de segurança é o caminho necessário para a construção de uma cidade democrática, onde exista apenas um tipo de cidadão.

\section{Palavras-chave}

Favela; cotidiano; segurança pública; representação; ação policial. 


\section{Abstract}

Silva, Eliana Sousa; Fonseca, Denise Pini Rosalem da (Advisor). The Context of Police Action in the Maré Slums: the search for new paths taking their protagonists into account. Rio de Janeiro, 2009. 460p. Thesis Doctoral - Departamento de Serviço Social, Pontifícia Universidade Católica do Rio de Janeiro.

Consists of a study of the activities of the military police in slums, specifically in Maré, a set of sixteen slums located in Leopoldina, Rio de Janeiro. The main goal of the research was to analyse the representations and practices of public security professionals focusing on the differentiated ways they perform within the same city. Its assumption is that the construction of new paradigms in the field of public policies requires a full understanding of the representations and experiences present in these spaces. This work presents a specific gaze at State action in the field of public security. I have analysed, in particular, police action in popular territories, as opposed to so-called formal spaces. I have tried to show such intervention as an element obeying to the rationale that guides the establishment and maintenance of the current social order, in which differentiated practices affirm identity characteristics conditioned by social assumptions based on distinctive social hierarchies and by the reproduction of a privatization process of autonomy in slums by Criminal Armed Groups, in general. In such a context, the State, which should guarantee public security to the whole polis, acts in slum areas without considering the contingencies and needs of their dwellers. This attitude naturalizes the use of violence as the guideline of police strategies to contain criminal groups associated to drug dealing, turned into the State's main target of crime combat in Brazilian urban areas. Hence, putting an end to differentiated forms of autonomy in the city and, as a result, to distinct modes of action of security forces is the necessary path to the construction of a democratic city, in which there is one only type of citizen.

\section{Keywords}

Slum; everyday life; public security; representation; police action. 


\section{Sumário}

\section{Volume I}

1. Motivações e premissas do estudo 34

1.1. A frente de batalha e a eleição do tema 34

1.2. Considerações primeiras sobre os vínculos entre objetividade e subjetividade $\quad 40$

1.3. Observações sobre os vínculos entre minha trajetória social e o tema do presente trabalho 48

2. Violência, cultura republicana e realidades das favelas 58

2.1. Notícias da "frente de batalha" 58

2.2. Um pressuposto da tese: uma razão sustenta a violência cotidiana, em suas diferentes formas

2.3. A hipótese: os limites da cultura republicana brasileira e privatização da soberania urbana no Rio de Janeiro determinam as formas tradicionais de ação policial nas favelas 68

2.4. A desigualdade brasileira e algumas razões para o déficit de rex publica 78

2.5. A Polícia Militar e sua crise histórica de identidade 92

3. A segurança pública no Rio de Janeiro a partir da década de 1980: os Direitos Humanos e os Grupos Criminosos Armados entram em cena

3.1. No tempo dos rituais de guerra e paz 100

3.2. O Governo Brizola como marco de referência na Segurança Pública 104

3.3. O Estado do Rio de Janeiro governado por Moreira Franco 113

3.4. A volta de Leonel Brizola ao governo do Estado 118

3.5. Marcelo Alencar é eleito governador do Estado 121

3.6. Anthony Garotinho se torna Governador 126

3.7. Rosinha Garotinho governadora 131

3.8. O mandato do governador Sérgio Cabral 134 
4.1. Apenas mais uma abordagem policial na favela 144

4.2. Representações sociais e o seu papel no estudo 147

$\begin{array}{ll}\text { 4.3. Sobre a vida cotidiana } & 157\end{array}$

5. O território da Maré e a vida cotidiana 166

5.1. Encontros com o poder do tráfico na Maré: o " desenrolo" 166

5.2. O território da Maré 174

5.3. Práticas cotidianas na Maré 183

5.4. O Batalhão da Polícia Militar na Maré 194

5.5. Práticas cotidianas dos policiais do $22^{\circ}$ Batalhão Maré 205

\section{Volume II}

6. Caminhos da pesquisa

6.1. Quando os números revelam destinos possíveis e dramas profundos 211

6.2. O papel da pesquisa de campo 215

6.2.1. A importância da coleta de dados 215

6.2.2. O desenho amostral 218

6.2.3. Instrumento de coleta 221

6.2.4. O trabalho de campo 222

6.3. Os dados revelados/reveladores 228

6.3.1. Perfis dos entrevistados 228

6.3.1.1. Perfil dos Moradores da Maré 228

6.3.1.2. Perfil dos integrantes entrevistados dos GCAs. 236

6.3.1.3. Perfil dos Policiais entrevistados do $22^{\circ}$ Batalhão 240

6.3.1.4 Sobre a percepção da Maré 245

6.3.1.5 Sobre a percepção da Violência 258

6.3.1.6 Percepção da atuação da polícia na Maré 280

6.3.1.7 Percepção global das Forças Policiais 307 
7.1. O contato singular com os profissionais da segurança 354

7.2. Buscando caminhos 358

7.3. A experiência do GPAE 365

7.4. A experiência do Município de Diadema - região metropolitana de São Paulo

7.5. A experiência do Município de Diadema - região metropolitana de São Paulo

7.6. A experiência de Jardim Angela em São Paulo

7.7. A lucidez animadora: a fala de um delegado da polícia do Rio de Janeiro

8. Conclusão de Percurso

9. Epílogo - Dando vida aos perfis: falas de protagonistas da "guerra" sobre o cotidiano da Maré

9.1. "Frente de Batalha": a violência percebida em outro espaço e tempo da Maré, e as consequências advindas

9.2. Sobre as falas e seus autores

9.3. Fala de uma moradora

9.4. Fala de integrante de uma facção criminosa da Maré

9.5. Dois policiais

11.3. Manifestações Públicas contra a violência policial em Favelas 
11.5.2. Segmento Grupos Criminosos Armados

11.6. Autorização do Comandante do $22^{\circ}$ Batalhão de Polícia Militar para realizar a pesquisa de campo 


\section{Lista de Tabelas}

\section{Volume I}

TABELA 1 - Homicídios dolosos registrados pela Polícia Civil na cidade do Rio de Janeiro de 1985 a 2006

TABELA 2 - Policiais mortos em serviço

no Estado do Rio de Janeiro de 2000 a 2006

TABELA 3 - Distribuição das ocorrências registradas

$21^{\text {a }}$ DP no período de 2004 a 2008, por favela

TABELA 4 - Distribuição dos registros de ocorrências

nas favelas da Maré entre 2004 e 2008,

por ano de referência

\section{Volume II}

TABELA 5 - Número de domicílios com entrevista realizada e de moradores entrevistados segundo a área de coleta.

TABELA 6 - Distribuição dos moradores entrevistados segundo o sexo por área de coleta

TABELA 7 - Distribuição dos moradores entrevistados segundo o tempo de residência na Maré por área de coleta.

TABELA 8 - Distribuição dos moradores entrevistados segundo a faixa etária por área de coleta.

TABELA 9 - Distribuição dos moradores entrevistados segundo a escolaridade por área de coleta.

TABELA 10 - Distribuição dos moradores entrevistados segundo a religião que professam por área de coleta.

TABELA 11 - Distribuição dos moradores entrevistados segundo a cor/raça declarada por área de coleta.

TABELA 12 - Distribuição dos moradores entrevistados segundo a situação em relação ao trabalho por área de coleta. 
TABELA 13 - Distribuição dos moradores entrevistados

que trabalham segundo a condição da atividade.

TABELA 14 - Distribuição dos integrantes do tráfico entrevistados segundo o tempo de residência na Maré.

TABELA 15 - Distribuição dos integrantes da milícia entrevistados segundo o tempo de residência na Maré.

TABELA 16 - Distribuição dos integrantes dos grupos criminosos armados entrevistados segundo a escolaridade declarada.

TABELA 17 - Distribuição dos integrantes do tráfico entrevistados segundo a escolaridade declarada.

TABELA 18 - Distribuição dos integrantes das milícias entrevistados segundo a escolaridade declarada.

TABELA 19 - Distribuição dos integrantes dos grupos criminosos Armados entrevistados segundo a cor/raça declarada.

TABELA 20 - Distribuição dos integrantes do tráfico entrevistados segundo a cor/raça declarada.

TABELA 21- Distribuição dos integrantes da milícia entrevistados segundo a cor/raça declarada.

TABELA 22- Distribuição dos integrantes dos grupos criminosos Armados entrevistados segundo a faixa etária.

TABELA 23- Distribuição dos integrantes do tráfico entrevistados segundo a faixa etária.

TABELA 24- Distribuição dos integrantes da milícia entrevistados segundo a faixa etária.

TABELA 25- Distribuição dos policiais entrevistados segundo a patente.

TABELA 26- Distribuição dos policiais entrevistados segundo a faixa etária.

TABELA 27- Distribuição dos policiais entrevistados segundo a escolaridade declarada.

TABELA 28- Distribuição dos policiais entrevistados segundo a cor/raça declarada.

TABELA 29- Distribuição dos policiais entrevistados segundo o local de moradia declarado. 
TABELA 30- Distribuição dos policiais entrevistados segundo a idade que tinham ao ingressar na corporação.

TABELA 31- Distribuição dos policiais entrevistados segundo o tempo em que trabalham na corporação.

TABELA 32- Distribuição dos policiais entrevistados segundo a faixa salarial declarada.

TABELA 33- Distribuição dos policiais entrevistados segundo a declaração de exercício de outra atividade além da policial.

TABELA 34- Distribuição dos policiais entrevistados segundo a função exercida no Batalhão.

TABELA 35- Respostas dos moradores ao quesito: você gosta de morar na Maré?

TABELA 36- Respostas dos moradores ao quesito: você gosta de morar na Maré?, por área de coleta, em percentuais.

TABELA 37- Respostas dos integrantes do tráfico e da milícia ao quesito: você gosta de morar na Maré?

TABELA 38 - Respostas dos policiais ao quesito: você gosta de trabalhar na Maré?

TABELA 39 - Respostas (estimuladas) dos policiais ao quesito, Por quê? - para aqueles que responderam gostar de trabalhar na Maré. TABELA 40 - Respostas (estimuladas) dos policiais ao quesito: por quê? - para aqueles que responderam não gostar de trabalhar na Maré.

TABELA 41 - Respostas dos moradores ao quesito:

o lugar onde você mora é favela?

TABELA 42 - Respostas dos integrantes do tráfico e da milícia ao quesito: o lugar onde você mora é favela?

TABELA 43 - Respostas (espontâneas) dos moradores ao quesito: qual é o aspecto mais positivo de morar na Maré?

TABELA 44 - Respostas (espontâneas) dos integrantes do tráfico ao quesito: qual é o aspecto mais positivo de morar na Maré?

TABELA 45 - Respostas (espontâneas) dos integrantes da milícia ao quesito: qual é o aspecto mais positivo de morar na Maré? 
TABELA 46 - Respostas (estimuladas) dos policiais ao quesito:

indique quais aspectos você acredita serem positivos

para os residentes na Maré?

TABELA 47 - Respostas (espontâneas) dos moradores ao quesito:

qual é o aspecto mais negativo de morar na Maré?

TABELA 48 - Respostas (espontâneas) dos integrantes

do tráfico ao quesito: qual é o aspecto mais

negativo de morar na Maré?

TABELA 49 - Respostas (espontâneas) dos integrantes

da milícia ao quesito: qual é o aspecto mais

negativo de morar na Maré?

256

TABELA 50 - Respostas (estimuladas) dos policiais ao quesito:

indique quais aspectos você acredita serem positivos

para os residentes na Maré?

TABELA 51 - Respostas (estimuladas) dos policiais ao quesito:

como você identifica, em geral, os moradores da Maré.

258

TABELA 52 - Respostas (estimuladas) dos moradores ao quesito:

com qual das definições de violência você mais se identifica?

259

TABELA 53 - Respostas (espontâneas) dos moradores

ao quesito: qual? - para aqueles que responderam

É quando uma pessoa ou grupo fere, de algum modo,

os direitos de outra pessoa ou grupo.

260

TABELA 54 - Respostas (estimuladas) dos policiais ao quesito:

com qual das definições de violência você mais se identifica?

TABELA 55 - Respostas (espontâneas) dos policiais

ao quesito: qual? - para aqueles que responderam

É quando uma pessoa ou grupo fere, de algum modo,

os direitos de outra pessoa ou grupo.

TABELA 56 - Respostas (estimuladas) dos integrantes do tráfico e da milícia ao quesito: Com qual das definições de violência você mais se identifica?

TABELA 57 - Respostas (espontâneas) dos integrantes do tráfico ao quesito: qual? - para aqueles que responderam 
É quando uma pessoa ou grupo fere,

de algum modo, a dignidade humana de outra pessoa ou grupo.

TABELA 58 - Respostas dos moradores, policiais, integrantes

do tráfico e integrantes da milícia ao quesito: você considera

a cidade do Rio de Janeiro violenta?

TABELA 59 - Respostas (espontâneas) dos moradores

ao quesito: por quê? - para aqueles que responderam

Sim, considero a cidade do Rio de Janeiro violenta.

TABELA 60 - Respostas (espontâneas) dos policiais ao quesito:

por quê? - para aqueles que responderam Sim, considero a

cidade do Rio de Janeiro violenta.

TABELA 61 - Respostas (espontâneas) dos integrantes do tráfico ao quesito: por quê? - para aqueles que responderam

Sim, considero a cidade do Rio de Janeiro violenta.

TABELA 62 - Respostas (espontâneas) dos integrantes da milícia ao quesito: por quê? - para aqueles que responderam

Sim, considero a cidade do Rio de Janeiro violenta.

TABELA 63 - Respostas de moradores, integrantes do tráfico e integrantes da milícia ao quesito, Você visita ou freqüenta outros lugares fora da Maré?

TABELA 64 - Respostas (estimuladas) dos integrantes do tráfico ao quesito: os lugares que você costuma visitar ou frequentar são... para aqueles que responderam Sim, costumam visitar ou frequentar outros lugares fora da Maré.

TABELA 65 - Respostas (estimuladas) dos integrantes da milícia ao quesito: os lugares que você costuma visitar ou frequentar são... para aqueles que responderam Sim, costumam visitar ou frequentar outros lugares fora da Maré.

TABELA 66 - Respostas (estimuladas) de moradores, policiais, integrantes do tráfico e integrantes da milícia ao quesito,: você considera que a violência na Maré...

TABELA 67 - Respostas (estimuladas) dos policiais ao quesito: em relação a outras favelas do Rio de Janeiro, a Maré é... 
TABELA 68 - Respostas (estimuladas) dos moradores ao quesito:

quando você está na Maré se sente...

TABELA 69 - Respostas (espontâneas) dos moradores ao quesito: por quê? - para aqueles que responderam que Quando estão na Maré se sentem...Tão seguros como quando circulam pelo resto da cidade ou Mais seguros do que quando circulam pelo resto da cidade.

TABELA 70 - Respostas (espontâneas) dos moradores ao quesito: por quê? para aqueles que responderam que Quando estão na Maré se sentem...Tão inseguros como quando circulam pelo resto da cidade ou Menos seguros do que quando circulam pelo resto da cidade.

TABELA 71 - Respostas (estimuladas) dos integrantes do tráfico ao quesito: quando você está na Maré se sente...

TABELA 72 - Respostas (estimuladas) dos integrantes da milícia ao quesito: quando você está na Maré se sente...

TABELA 73 - Respostas (estimuladas) dos moradores ao quesito: dentre os tipos de violência abaixo, assinale a(s) que já ocorreu(ram) com você nos últimos 12 meses .

TABELA 74 - Respostas (estimuladas) dos moradores ao quesito:

em caso afirmativo,a(s) situação(ões) de violência ocorreu(ram) para aqueles que sofreram algum tipo de violência nos últimos 12 meses.

TABELA 66 - Respostas (estimuladas) dos policiais ao quesito: nos últimos 12 meses, você se envolveu em alguma situação dentro da Maré a qual considerou violenta?

TABELA 76 - Respostas (estimuladas) dos policiais ao quesito: nos últimos 12 meses, você assistiu a alguma situação a qual considerou violenta na Maré?

TABELA 77 - Respostas (estimuladas) dos policiais ao quesito: assinale, dentre os tipos de violência abaixo, a(s) que você presenciou nos últimos 12 meses na Maré - para aqueles que afirmaram Ter assistido nos últimos 12 meses a alguma situação a qual considerou violenta na Maré. 
TABELA 78 - Respostas (estimuladas) dos moradores ao quesito: para cada uma das formas de violência abaixo, diga se, na Maré, elas acontecem com muita frequência, se acontecem com freqüência raramente ou nunca acontecem.

TABELA 79 - Respostas (estimuladas) dos integrantes do tráfico ao quesito: para cada uma das formas de violência abaixo, diga se, na Maré, elas acontecem com muita frequência, se acontecem com frequência, raramente ou nunca acontecem.

TABELA 80 - Respostas (estimuladas) dos integrantes da milícia ao quesito: para cada uma das formas de violência abaixo, diga se, na Maré, elas acontecem com muita frequência, se acontecem com frequência, raramente ou nunca acontecem.

TABELA 81 - Respostas (estimuladas) de moradores, policiais, integrantes do tráfico e integrantes da milícia ao quesito: em relação à afirmativa abaixo, diga se você concorda plenamente, concorda em parte, discorda em parte ou discorda totalmente. TABELA 82 - Respostas dos moradores ao quesito: em relação à afirmativa abaixo, diga se você concorda. TABELA 83 - Respostas (estimuladas) dos policiais ao quesito: em relação à afirmativa abaixo, diga se você concorda plenamente, concorda em parte, discorda em parte ou discorda totalmente. TABELA 84 - Respostas (estimuladas) dos moradores ao quesito: na sua opinião, o uso do blindado (Caveirão) é positivo ou negativo para o policial.

TABELA 85 - Respostas (estimuladas) dos moradores ao quesito: na sua opinião, o uso do blindado (Caveirão) é positivo ou negativo para o morador.

TABELA 86 - Respostas (estimuladas) de moradores, policiais, integrantes do tráfico e integrantes da milícia ao quesito, Em relação à afirmativa abaixo, diga se você concorda plenamente, concorda em parte, discorda em parte ou discorda totalmente.

TABELA 87 - Respostas (estimuladas) de moradores, policiais e integrantes da milícia ao quesito: em relação à afirmativa abaixo, diga se você 
concorda plenamente, concorda em parte, discorda em parte ou discorda totalmente.

TABELA 88 - Respostas (estimuladas) de moradores, policiais, integrantes do tráfico e integrantes da milícia ao quesito: em relação à afirmativa abaixo, diga se você concorda plenamente, concorda em parte, discorda em parte ou discorda totalmente.

TABELA 89 - Respostas (estimuladas) de moradores, policiais, integrantes do tráfico e integrantes da milícia ao quesito: em relação à afirmativa abaixo, diga se você concorda plenamente, concorda em parte, discorda em parte ou discorda totalmente.

TABELA 90 - Respostas (estimuladas) de moradores e policiais ao quesito: em relação à afirmativa abaixo, diga se você concorda plenamente, concorda em parte, discorda em parte ou discorda totalmente.

TABELA 91 - Respostas (estimuladas) de moradores e policiais ao quesito: em relação à afirmativa abaixo, diga se você concorda plenamente, concorda em parte, discorda em parte ou discorda totalmente.

TABELA 92 - Respostas (estimuladas) de moradores e policiais ao quesito: em relação à afirmativa abaixo, diga se você concorda plenamente, concorda em parte, discorda em parte ou discorda totalmente.

TABELA 93 - Respostas (estimuladas) de moradores, policiais, integrantes do tráfico e integrantes da milícia ao quesito: em relação à afirmativa abaixo, diga se você concorda plenamente, concorda em parte, discorda em parte ou discorda totalmente.

TABELA 94 - Respostas (estimuladas) dos policiais ao quesito: em relação à afirmativa abaixo, diga se você concorda plenamente, concorda em parte, discorda em parte ou discorda totalmente.

TABELA 95 - Respostas (estimuladas) de moradores, integrantes do tráfico e integrantes da milícia ao quesito: em relação à afirmativa abaixo, diga se você concorda plenamente, concorda em parte, discorda em parte ou discorda totalmente.

TABELA 96 - Respostas (estimuladas) de moradores e policiais 
ao quesito: em relação à afirmativa abaixo, diga se você concorda plenamente, concorda em parte, discorda em parte ou discorda totalmente.

TABELA 97 - Respostas (estimuladas) de integrantes do tráfico e integrantes da milícia ao quesito - em relação à afirmativa abaixo, diga se você concorda plenamente, concorda em parte, discorda em parte ou discorda totalmente.

TABELA 98 - Respostas (estimuladas) de moradores, policiais, integrantes do tráfico e integrantes da milícia ao quesito: em relação à afirmativa abaixo, diga se você concorda plenamente, concorda em parte, discorda em parte ou discorda totalmente.

TABELA 99 - Respostas (estimuladas) de moradores e policiais ao quesito: em relação à afirmativa abaixo, diga se você concorda plenamente, concorda em parte, discorda em parte ou discorda totalmente.

TABELA 100 - Respostas (estimuladas) de moradores, policiais, integrantes do tráfico e integrantes da milícia ao quesito: em relação à afirmativa abaixo, diga se você concorda plenamente, concorda em parte, discorda em parte ou discorda totalmente. TABELA 101 - Respostas (estimuladas) de moradores, policiais, integrantes do tráfico e integrantes da milícia ao quesito: em relação à afirmativa abaixo, diga se você concorda plenamente, concorda em parte, discorda em parte ou discorda totalmente.

TABELA 102 - Respostas (estimuladas) de moradores, policiais, integrantes do tráfico e integrantes da milícia ao quesito: em relação à afirmativa abaixo, diga se você concorda plenamente, concorda em parte, discorda em parte ou discorda totalmente: $A$ morte ocasional de moradores faz parte da guerra contra o crime e essa estratégia não pode ser mudada.

TABELA 103 - Respostas (estimuladas) de moradores, policiais, integrantes do tráfico e integrantes da milícia ao quesito: em relação à afirmativa abaixo, diga se você concorda plenamente, concorda em parte, discorda em parte ou discorda totalmente. As ações 
cumpridas pela polícia na Maré costumam ser positivas para a comunidade local e não devem mudar.

TABELA 104 - Respostas (estimuladas) de moradores, policiais, integrantes do tráfico e integrantes da milícia ao quesito: em relação à afirmativa abaixo, diga se você concorda plenamente, concorda em parte, discorda em parte ou discorda totalmente. A polícia não tem como agir de forma diferente da atual enquanto houver a presença das facções criminosas.

TABELA 105 - Respostas (estimuladas) de moradores, policiais, integrantes do tráfico e integrantes da milícia ao quesito: em relação à afirmativa abaixo, diga se você concorda plenamente, concorda em parte, discorda em parte ou discorda totalmente. A polícia precisa mudar a forma de atuar na comunidade para não colocar os moradores em risco.

TABELA 106 - Respostas (estimuladas) de moradores, policiais, integrantes do tráfico e integrantes da milícia ao quesito: em relação à afirmativa abaixo, diga se você concorda plenamente, concorda em parte, discorda em parte ou discorda totalmente. As drogas deveriam ser discriminalizadas, pois o combate ao tráfico gera mais morte e violência do que o consumo de drogas.

TABELA 107 - Respostas (estimuladas) de moradores, policiais, integrantes do tráfico e integrantes da milícia ao quesito: Em relação à afirmativa abaixo, diga se você concorda plenamente, concorda em parte, discorda em parte ou discorda totalmente. É necessário e positivo que a comunidade tenha segurança pública oferecida pelo Estado/Governo e que o morador tenha seus direitos devidamente respeitados.

TABELA 108 - Respostas (estimuladas) de moradores, policiais, integrantes do tráfico e integrantes da milícia ao quesito: Em relação à afirmativa abaixo, diga se você concorda plenamente, concorda em parte, discorda em parte ou discorda totalmente. A criação do Batalhão de Polícia na Maré contribuiu para diminuir a violência na região.

TABELA 109 - Respostas (estimuladas) de moradores e policiais 
ao quesito: Em relação à afirmativa abaixo, diga se você concorda plenamente, concorda em parte, discorda em parte ou discorda totalmente.

TABELA 110 - Respostas (estimuladas) de moradores, integrantes do tráfico e integrantes da milícia ao quesito: sua avaliação da atuação da polícia na Maré, em geral, é...

TABELA 111 - Respostas (estimuladas) de policiais ao quesito: Sua avaliação da atuação da polícia na Maré, em geral, é...

TABELA 112 - Respostas de moradores ao quesito: a atividade profissional do policial é valorizada pela sociedade?

TABELA 113. Respostas (estimuladas) de policiais, integrantes do tráfico e integrantes da milícia ao quesito: Você considera a atividade profissional do policial pouco valorizada pela sociedade? TABELA 114 - Respostas de moradores ao quesito: você acha que o salário da polícia é baixo para a tarefa que ele cumpre?

TABELA 115 - Respostas (estimuladas) de moradores, policiais, integrantes do tráfico e integrantes da milícia ao quesito: em relação à afirmativa abaixo, diga se você concorda plenamente, concorda em parte, discorda em parte ou discorda totalmente. A cor da pele de uma pessoa influencia na forma como ela é tratada pela polícia. TABELA 116 - Respostas (estimuladas) de moradores, policiais, integrantes do tráfico e integrantes da milícia ao quesito: você acredita que a polícia atua da mesma forma em todas as partes da cidade do Rio de Janeiro?

TABELA 117 - Respostas (estimuladas) de moradores, policiais, integrantes do tráfico e integrantes da milícia ao quesito: você já presenciou alguma vez no seu local de moradia algum agente policial cometendo algum ato que você considera ilegal ou antiético em se tratando de um policial?

TABELA 118 - Respostas (estimuladas) dos moradores ao quesito: Em caso afirmativo, qual? - para aqueles que responderam Sim, já presenciaram no local de moradia um agente policial cometendo um ato que consideram ilegal ou antiético. 
TABELA 119 - Respostas (estimuladas) dos integrantes do tráfico ao quesito: em caso afirmativo, qual? - para aqueles que responderam Sim, já presenciaram no local de moradia um agente policial cometendo um ato que consideram ilegal ou antiético.

TABELA 120 - Respostas (estimuladas) dos integrantes da milícia ao quesito: em caso afirmativo, qual? - para aqueles que responderam Sim, já presenciaram no local de moradia um agente policial cometendo um ato que consideram ilegal ou antiético.

TABELA 121 - Respostas (espontâneas) dos policiais ao quesito: em caso afirmativo, qual? - para aqueles que responderam Sim, já presenciaram no local de moradia um agente policial cometendo um ato que consideram ilegal ou antiético.

TABELA 122 - Respostas (estimuladas) de moradores, policiais, integrantes do tráfico e integrantes da milícia ao quesito: você considera que a maioria dos policiais é honesta?

TABELA 123 - Respostas de moradores ao quesito: você recorreu ao auxilio da polícia em alguma situação do cotidiano em que isso seria cabível?

TABELA 124 - Respostas de policiais ao quesito: a população da Maré recorre ao auxílio da polícia nas situações de sua vida cotidiana em que isso se faz necessário? TABELA 125 - Respostas dos moradores ao quesito: Como você Avalia a resposta da polícia quando é solicitada?

TABELA 126 - Respostas dos moradores ao quesito: Como você Avalia a resposta da polícia quando é solicitada? - Exclusivamente para aqueles que já recorreram ao auxilio da polícia em alguma situação do cotidiano.

TABELA 127 - Respostas dos moradores ao quesito: na sua opinião, a polícia tem condições de atuar dentro das favelas de forma melhor da que atua hoje em dia?

TABELA 128 - Respostas (estimuladas) de policiais, integrantes do tráfico e integrantes da milícia ao quesito: você acredita que a polícia deveria trabalhar de uma maneira diferente na Maré e nas favelas, em geral? 
TABELA 129 - Respostas dos policiais ao quesito: na sua opinião, a polícia tem condições de atuar dentro das favelas de forma melhor da que atua hoje em dia?

TABELA 130 - Respostas dos policiais ao quesito: você acredita que a atual política de segurança pública no estado é eficiente no combate à criminalidade? Na sua opinião, a polícia tem condições de atuar dentro das favelas de forma melhor da que atua hoje em dia? 320 


\section{Lista de Figuras}

FIGURA 131 - Fonte: Marcelo Régua, Jornal O Dia, 2 de outubro de 2006, p. 19. Revolta dos moradores pela morte da criança Renan da Costa Ribeiro, ocorrida em frente ao $22^{\circ}$ Batalhão de Polícia Militar no dia 1 de outubro de 2006, na favela Nova Holanda, Maré.

FIGURA 132 - Fonte: Escola de Fotógrafos Populares, Arquivo Imagens do Povo, Observatório de Favelas, c. 2008. Blindado estacionado na Rua Bittencourt Sampaio na favela Nova Holanda, Maré, no dia da realização da Conferência Livre na Maré sobre Segurança Pública. FIGURA 133 - Fonte: Escola de Fotógrafos Populares, Arquivo Imagens do Povo, Observatório de Favelas, c. 2008. Favela Nova Holanda, rua em frente ao CIEP Hélio Smidt. Dia das eleições do primeiro turno para escolha do Prefeito e Vereadores da cidade do Rio de Janeiro. FIGURA 134 - Fonte: Escola de Fotógrafos Populares, Arquivo Imagens do Povo, Observatório de Favelas, c. 2009. Incursão policial no Morro Pavão-Pavãozinho numa operação denominada Choque de Ordem. FIGURA 135 - Fonte: Escola de Fotógrafos Populares, Arquivo Imagens do Povo, Observatório de Favelas, c. 2006. Revolta dos moradores pela morte da criança Renan da Costa Ribeiro, ocorrida em frente ao $22^{\circ}$ Batalhão de Polícia Militar no dia 1 de outubro de 2006, na favela Nova Holanda, Maré.

FIGURA 136 - Fonte: Escola de Fotógrafos Populares, Arquivo Imagens do Povo, Observatório de Favelas, 2008. Favela Nova Holanda, rua Sargento Silva Nunes. Muro da Escola Municipal Nova Holanda. Ocupação do Exército em função das Eleições Municipais na cidade do Rio de Janeiro. 
FIGURA 137 - Fonte: Escola de Fotógrafos Populares, Arquivo Imagens do Povo, Observatório de Favelas, 2008. Favela Nova Holanda, rua Sargento Silva Nunes. Muro da Escola Municipal Nova Holanda. Ocupação do Exército em função das Eleições Municipais na cidade do Rio de Janeiro.

FIGURA 138 - Fonte: Escola de Fotógrafos Populares, Arquivo

Imagens do Povo, Observatório de Favelas, 2009. Operação policial na favela Baixa do Sapateiro, Maré, por ocasião da morte de um adolescente de 17 anos, Felipe dos Santos, assassinado na troca de tiro entre a polícia e os GCAs.

FIGURA 139 - Fonte: Agência Estado. On line. Pedro Dantas.

Operação do Core no Morro da Mineira, Catumbi. Rio de Janeiro. FIGURA 140 - Fonte: Escola de Fotógrafos Populares, Arquivo Imagens do Povo, Observatório de Favelas, c. 2008. Esquina de uma das ruas da Favela Baixa do Sapateiro, Maré, após confrontos entre distintos grupos armados.

FIGURA 141 - Fonte: Escola de Fotógrafos Populares, Arquivo Imagens do Povo, Observatório de Favelas, 2007. Laje de uma casa na Favela Nova Holanda, Maré. FIGURA 142 - Fonte: Escola de Fotógrafos Populares, Arquivo Imagens do Povo, Observatório de Favelas, 2007. Local chamado pelos moradores de "miolo", próximo à Rua Principal em Nova Holanda, Maré.

FIGURA 143 - Fonte: Escola de Fotógrafos Populares, Arquivo Imagens do Povo, Observatório de Favelas, 2007. 9a edição do evento "Batendo de Frente" o qual participaram artistas de várias favelas do Rio de Janeiro. Homenagem ao rap Jagal. Grafite pintado pelo artista Tito New York. Centro, Rio de Janeiro. FIGURA 144 - Fonte: Escola de Fotógrafos Populares, Arquivo Imagens do Povo, Observatório de Favelas, 2008. Vendedor ambulante num momento de brincadeira com crianças na favela Nova Holanda. 
FIGURA 145 - Fonte: Escola de Fotógrafos Populares, Arquivo Imagens do Povo, Observatório de Favelas, 2004.

Crianças brincando em cima da passarela 10 da Av. Brasil, em frente a Maré.

FIGURA 146 - Fonte: Escola de Fotógrafos Populares, Arquivo Imagens do Povo, Observatório de Favelas, 2004. Moradora em frente a residência na Favela rua Tancredo Neves, Nova Holanda, Maré.

FIGURA 147 - Fonte: Escola de Fotógrafos Populares, Arquivo Imagens do Povo, Observatório de Favelas, 2006.

Final de tarde na área aberta do Posto de coleta de Lixo da Companhia de Limpeza Urbana, Comlurb, localizado na Nova Holanda, Maré.

FIGURA 148 - Fonte: Escola de Fotógrafos Populares, Arquivo Imagens do Povo, Observatório de Favelas, c 2007. Atividade física para grupo da $3^{a}$ idade, na Praça do Valão, Maré. FIGURA 149 - Fonte: Escola de Fotógrafos Populares, Arquivo Imagens do Povo, Observatório de Favelas, c 2006. Passeata de famílias de diferentes favelas do Rio de Janeiro, que tiveram parentes vítimas da violência policial.

Centro do Rio de Janeiro.

FIGURA 150 - Fonte: Escola de Fotógrafos Populares, Arquivo Imagens do Povo, Observatório de Favelas, 2005.

Passeata de moradores de Nova Iguaçu, Baixada Fluminense, por ocasião da chacina policial que matou 29 pessoas.

FIGURA 151 - Fonte: Escola de Fotógrafos Populares, Arquivo Imagens do Povo, Observatório de Favelas, 2008.

Passeata de moradores da Maré nas ruas da Maré e Av. Brasil, por ocasião da morte da criança de 8 anos, Matheus Rodrigues. FIGURA 152 - Fonte: Escola de Fotógrafos Populares, Arquivo Imagens do Povo, Observatório de Favelas, 2008. Passeata de moradores da Maré nas ruas da Maré e Av. Brasil, por ocasião da morte da criança de 8 anos, Matheus Rodrigues. 
FIGURA 153 - Fonte: Escola de Fotógrafos Populares, Arquivo Imagens do Povo, Observatório de Favelas, 2008.

Passeata de moradores da Maré nas ruas da Maré e Av. Brasil, por ocasião da morte do adolescente de 17 anos, Felipe Santos.

FIGURA 154 - Fonte: Escola de Fotógrafos Populares, Arquivo Imagens do Povo, Observatório de Favelas, 2006.

Passeata denominada "Viva a Criança Viva" de moradores da Maré. Local Av. Brasil, por ocasião da morte da Rena da Costa.

FIGURA 155 - Fonte: Escola de Fotógrafos Populares, Arquivo Imagens do Povo, Observatório de Favelas, 2006. Passeata denominada "Viva a Criança Viva" de moradores da Maré. Local: Av. Brasil, por ocasião da morte da Rena da Costa. FIGURA 156 - Fonte: Escola de Fotógrafos Populares, Arquivo Imagens do Povo, Observatório de Favelas, 2008. Porta da residência de Matheus Rodrigues, criança de 8 anos, na Baixa do Sapateiro, Maré, no dia que foi atingido por um tiro. FIGURA 157 - Fonte: Escola de Fotógrafos Populares, Arquivo Imagens do Povo, Observatório de Favelas, 2005. Poste localizado na área de divisa entre 2 grupos armados, entre a Baixa do Sapateiro e o Parque Maré.

FIGURA 158 - Fonte: Escola de Fotógrafos Populares, Arquivo Imagens do Povo, Observatório de Favelas, 2005. Igreja localizada na área de divisa entre 2 grupos armados, entre a Baixa do Sapateiro e o Parque Maré.

FIGURA 159 - Fonte: Escola de Fotógrafos Populares, Arquivo Imagens do Povo, Observatório de Favelas, 2009. Enterro de 4 vítimas, moradores do Parque União, Maré, por ocasião dos confrontos entre a polícia e os GCAs. FIGURA 160 - Fonte: Escola de Fotógrafos Populares, Arquivo Imagens do Povo, Observatório de Favelas, 2005. Poste localizado na área de divisa entre 2 grupos armados, entre a Baixa do Sapateiro e o Parque Maré.

FIGURA 161 - Fonte: Escola de Fotógrafos Populares, Arquivo Imagens do Povo, Observatório de Favelas, 2009. 
Enterro de 4 vítimas, moradores do Parque União, Maré, por ocasião dos confrontos entre a polícia e os GCAs.

FIGURA 162 - Fonte: Escola de Fotógrafos Populares, Arquivo Imagens do Povo, Observatório de Favelas, 2003.

Enterro da criança Renan da Costa, de 3 anos, assassinado em Nova Holanda, numa incursão policial.

FIGURA 163 - Fonte: Escola de Fotógrafos Populares,

Arquivo Imagens do Povo, Observatório de Favelas, 2009.

Conferência Livre da Maré. Discussão nos grupos temáticos.

FIGURA 164 (a, b, c e d) - Instrumentos de Coleta de Dados

Segmento Morador

FIGURA 165 ( $a$, b, c e d) - Instrumentos de Coleta de Dados Segmento Grupos Criminosos Armados

FIGURA 166 ( $a$, b, c e d) - Instrumentos de Coleta de Dados

Segmento Policial do $22^{\circ}$ Batalhão de Polícia Militar

FIGURA 167 - Autorização do Comandante do $22^{\circ}$ Batalhão de Polícia Militar para realizar a pesquisa de campo 
Entre muitas outras coisas, tu eras para mim uma janela através da qual podia ver as ruas. Sozinho não o podia fazer. 